\title{
Combining individual and collective management of animal manure to reduce environmental impacts on a territory scale
}

\author{
J.-M. Paillat ${ }^{\text {a }}$ and F. Guerrin ${ }^{\text {a,b }}$ \\ ${ }^{a}$ CIRAD, UR Recyclage et risque, F-97408 Saint-Denis, La Réunion, France \\ ${ }^{b}$ INRA, UR Biométrie et Intelligence artificielle, F-31326 Castanet-Tolosan, France \\ Email:_francois.guerrin@cirad.fr
}

\begin{abstract}
Combining life cycle analysis (LCA) and simulation modelling (SM) has been used to assess and improve a collective manure management plan set up in Brittany (north-western France) by a group of farmers to comply with current Nitrogen reduction regulations in agriculture. The plan studied aimed at organizing the spreading of slurry surpluses produced by 11 pig farms (representing 57.6 tons N/year) on crop land loaned by 22 crop farms located approximately $44 \mathrm{~km}$ away.
\end{abstract}

LCA was used according to its normalized methodology to statically assess the potential environmental impacts based on 4 criteria: eutrophication, climate change, acidification and use of non-renewable energy.

COMET, the dynamic systems model used in this study, has been implemented with the Vensim ${ }^{\circledR}$ software by coupling:

- logistics models, to simulate the transportation and spreading of manure, both at the individual (within farms) and collective (transfer plan) levels;

- biophysical models, mainly empirical, to simulate ammonia $\left(\mathrm{NH}_{3}\right)$ and methane $\left(\mathrm{CH}_{4}\right)$ emissions as the main criteria of the environmental evaluation with COMET.

The approach encompassed four steps that alternated between the LCA and SM methodologies:

(i) LCA was initially performed to assess the environmental impacts of two disposal scenarios, i.e. slurry biological treatment or transfer for application to remote crop farms. The analysis concluded the transfer scenario had the least environmental impact as, if properly implemented, it may save on the use of chemical fertilizers.

(ii) SM using the COMET model simulated the logistics and agricultural feasibility of the transfer scenario to verify to what extent the collective management plan can be fully completed in due time on appropriate cropping systems.

(iii) A second iteration of LCA was made to assess the environmental impacts of simulated variants of the transfer scenario, this time using simulation outputs instead of reference database information. These analyses showed important differences of impacts among the management options simulated.

(iv) Finally, simulations with COMET were performed to examine the interaction between the individual level of management (manure spreading within animal farms) and the collective level (manure transfer plan to land loaners' crop farms). The variability of impacts between individual situations was very high, suggesting that farmer equipment should be adapted and collective rules made flexible to secure farm stock management.

Beyond the results from the first three steps, this paper emphasises the more realistic outcomes achieved in the fourth and final step. This step allowed the variability of individual pig farm logistics and gas emissions to be analyzed, as well as simple techniques, that could be implemented by individual farmers to improve the whole system agricultural and environmental performance, to be checked. This paper concludes that benefits can be drawn from combining LCA and SM, as this makes possible to consider the diversity of actual farming situations and practices and, so, to design management rules balancing individual and collective needs.

Keywords: Simulation modelling, Animal waste management, Individual-collective interaction, Agricultural production systems, Environmental impact assessment. 


\section{INTRODUCTION}

Several simulation models to assess management strategies of livestock wastes on a farm or territory scale have been devised (Guerrin and Paillat, 2003). These models are based on an 'Action-Flow-Stock' ontology, in which elementary production units are represented by material stocks, with inflows and outflows being controlled by farmers' actions (Guerrin, 2009). Agricultural system functioning is thus seen as the interaction between natural biophysical processes and man-controlled workable processes. While developing the side of representing human activities in agricultural systems (Guerrin, 2009), assessing the environmental impacts of simulated management strategies is also performed. Although some output variables of these models can account for some of the impacts, provided sub-models exist, this approach appeared limited to account completely for both local and global environmental impacts.

Other research is investigating the application of Life Cycle Analysis (LCA) to multi-criteria assessment of agricultural systems (Basset-Mens and van der Werf, 2005; Aubin and van der Werf, 2009). This "cradle to grave" approach is relevant so far as it takes into account both the direct and indirect potential impacts of a product. However, it has the drawback of considering 'standard' production systems, with 'average' flows and impacts, by using parameters taken from international reference databases. Although some research has been done to remediate these defects (Payraudeau and van der Werf, 2005), it is a static, accounting approach that disregards the dynamics and spatial aspects linked to actual farming practices and processes. Being relatively removed from the reality of varied and adaptive farming practices makes LCA probably less relevant than simulation modelling (SM) if the aim is to advise farmers on their management.

The LCA approach, aggregating emission flows into impact categories, and the SM approach, simulating some of these flows dynamically, may however be regarded as complementary. Hence, combining both approaches has been conducted in two cases: a pig farm, using the MELODIE model (Rigolot et al., 2010), and a collective slurry management plan, using the model called COMET (COllective Management of Effluents on a Territory scale). The second case is presented here. Both cases were located in Ille-et-Vilaine, Brittany (north-western France), where more than half of the cantons are classified as "Structural Surplus Areas", where more than $170 \mathrm{~kg}$ nitrogen of animal origin per spreadable hectare are produced. The regulation, EU Nitrate directive 91/676/CEE, which aims at reducing excess nitrogen, imposes the requirement on farmers that, either, excess nitrogen is treated, or otherwise exported to areas with nitrogen burdens less than $140 \mathrm{~kg}$ $\mathrm{N}$ of animal origin per ha. To comply with this regulation, a group of livestock farmers set up a collective slurry spreading plan. In this study, a group of 11 pig farms is considered that produce 'Mix' slurry (from sows and piglets) and 'FP' slurry (from fatteners). Around 2/3 of the total FP slurry (57.6 tons N/year) is to be spread on 1024 ha of land, loaned by 22 crop farmers located 33 to $55 \mathrm{~km}$ away from the pig farms. Based on this, the main research question addressed is to find how the use of LCA and SM can help better manage manure by balancing the individual farm and collective territory managements.

This paper is organized as follows. Section 2 describes the methodology which encompasses four successive steps alternating between LCA and SM, and the main results obtained for the first three steps. Section 3 provides details on the fourth step, in which the variability of pig farm logistics and gas emissions were analysed and simple techniques that could be implemented by individual farmers to improve the whole system performances were checked. Section 4 discusses the benefits drawn from combining LCA and SM and concludes with the necessity to consider the diversity of actual farming situations and practices.

\section{METHODOLOGY AND PRELIMINARY RESULTS}

\subsection{Life Cycle Analysis (LCA): comparison of two management scenarios}

Firstly, the environmental performance of two manure disposal scenarios envisaged by local farmers was compared: 1) biological treatment, very widespread in Brittany, and 2) transfer of raw slurry to remote agricultural land loaners (Lopez-Ridaura et al., 2008a). LCA was used to assess the potential environmental impacts of these two scenarios based on four criteria: eutrophication ( $\mathrm{kg} \mathrm{PO}_{4}$-eq.), climate change $\left(\mathrm{kg} \mathrm{CO}_{2}\right.$ eq.), acidification ( $\mathrm{kg} \mathrm{SO}_{2}$-eq.) and use of non-renewable energy (MJ Lower Heating Value-eq.). For climate change, both scenarios have the same impact. However, when the substitution of slurry for chemical fertilizers is considered the "Transfer" scenario has a much lower impact in terms of eutrophication, acidification and energy use (Lopez-Ridaura et al., 2008a). These results assume the transfer plan is fully completed and allows farmers to save on the use of chemical fertilizers. On-farm slurry storage crucially influences gaseous emissions: ammonia $\left(\mathrm{NH}_{3}\right)$ and methane $\left(\mathrm{CH}_{4}\right)$. Ammonia volatilization following field slurry application is low, based on the assumption farmers practise deep injection of slurry into the soil. 
Paillat and Guerrin, Combining individual and collective management of animal manure on a territory scale

\subsection{Simulation Modelling (SM): feasibility of an intended slurry management plan}

As LCA emphasized, the actual feasibility of the transfer scenario has implications for its performance. The COMET model was used to check this according to logistics (number and availability of transport and spreading vehicles, speeds, capacities of storage, etc.), crops (cropping plan, fertilization needs), soils (hydromorphy) and climate (pluviometry) (Lopez-Ridaura et al., 2007). COMET, implemented with the Ven$\operatorname{sim}^{\circledR}$ software, is based on the coupling of several models:

- Logistics models simulate the transportation and spreading of manure, both at the individual (within farms) and collective (transfer plan) levels. The MAGMA (Guerrin, 2001) and APPROZUT (Guerrin, 2004) models, respectively, were used for this, coupled together with an original module accounting for slurry spreading with an automotive spreader (Terragator ${ }^{\mathbb{R}}$ ) used at the land loaners'.

- Semi-empirical biophysical models simulate $\mathrm{NH}_{3}$ and $\mathrm{CH}_{4}$ emissions as the main criteria of environmental evaluation. The STAL model (Morvan and Leterme, 2001) simulates $\mathrm{NH}_{3}$ emissions after spreading and an original module accounts for $\mathrm{NH}_{3}$ and $\mathrm{CH}_{4}$ emissions during storage, based on equations borrowed from Loyon et al. (2007) and Pelletier et al. (2006).

As used in this case study, COMET simulates the transfer of slurry from several pig farms that also produce crops to several land loaners' crop farms that also produce livestock (Fig. 1). Mix slurry tanks (fed by sows and piglets) can also possibly receive stock overflows of FP slurry (from fatteners). Only FP slurry is delivered to the land loaners of the collective spreading plan to be applied on their crops (winter cereals, maize, rape and grassland), in addition to their own livestock manure. FP slurry is shipped by $25 \mathrm{~m}^{3}$-trucks and unloaded into a $200-\mathrm{m}^{3}$ mobile tank located close to the land loaners' crops where it is applied by the Terragator $^{B}$. This latter is assumed to have a nominal spreading outflow of $60 \mathrm{~m}^{3} \mathrm{~h}^{-1}$ and work $10 \mathrm{hrs}$ per day, 5 days a week, all year round. Independent of collective management, Mix slurry is applied by pig farmers to their own crops (same as the land loaners') with their own equipment (tractors with slurry tankers).

The main environmental indicators simulated by $\mathrm{COMET}$ are $\mathrm{NH}_{3}$ emissions at storage and spreading, $\mathrm{CH}_{4}$ emissions at storage, stock overflow (assumed to denote water pollution risk by nitrates), and nitrogen that is added as chemical fertilizers to meet crop requirements when slurry spreading is incomplete (Fig. 1).

Based on actual farm characteristics, simulations have demonstrated the sensitivity of the collective spreading plan to logistics (e.g. number of trucks, speed of spreading) and climatic conditions. Consequently, the plan is not always completed annually, e.g. on winter cereals or maize in early spring, in

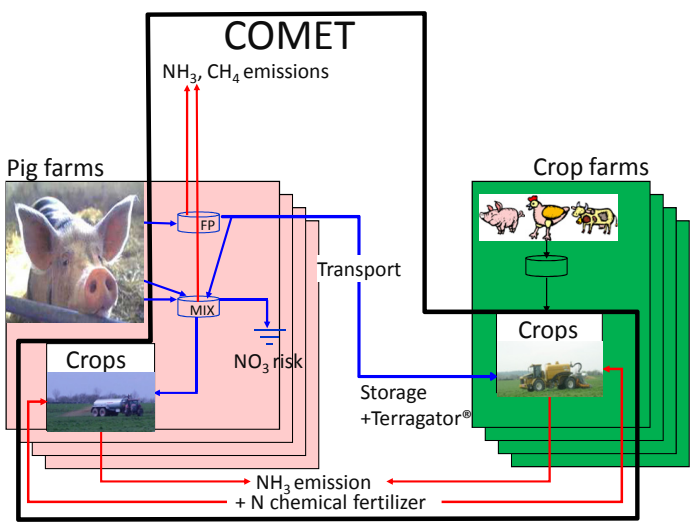

Figure 1. Agricultural system as represented by the COMET model. years with wet winters, on poorly drained soils. Reduced availability of the Terragator ${ }^{\circledR}$ (e.g. 3 instead of 5 days per week) also greatly affects the successful application of the plan as it may reduce manure applications on winter cereals to less than half the required amount when the soil and climate conditions are unfavourable. Introducing technical or organizational changes in simulations, namely modifying crop rotation (e.g. substituting $10 \%$ of winter cereals acreage for rape onto which manure applications are done in summertime), dramatically improves the successful application of the spreading plan (Paillat et al., 2009).

\subsection{LCA: Environmental assessment of the 'Transfer' scenario based on simulation outputs}

The third step used LCA again to assess the 'Transfer' scenario but, this time, along with the volumes of slurry spread and the gas emissions simulated by COMET, instead of average values as in step 1 . The simulation outputs corresponded to the above mentioned management alternatives: varying the length of delay after rainfall to access fields according to the soil quality (hydromorphy) and availability of spreading equipment. These analyses showed large gaps between LCA in step 1, based on 'average' coefficients (cf. § 2.1; LopezRidaura et al., 2008a), and those based on COMET outputs. The eutrophication and acidification impacts are higher from LCA used in this step than those from step 1. These results are due to underestimating $\mathrm{NH}_{3}$ 
emissions as slurry was assumed to be injected into the soil for all crops whereas, more realistically, this only occurs for maize and rape in the COMET simulations. Discrepancies as large as $60 \%$ are noted among these management variant analyses, particularly for the climate change criterion. They are due mainly to the amounts of $\mathrm{CH}_{4}$ emitted, which depends on the slurry storage duration, which is linked to the actual realization of slurry field applications (Lopez-Ridaura et al., 2008b).

\subsection{SM: analysing the variability of environmental performances among individual farms}

Although in the previous analyses ( $§ 2.1$ to 2.3 ) aggregated results were used to assess global system performances, COMET simulates each farm's parameters (slurry stocks, amounts applied to crops, N concentrations, gaseous emissions, etc.) meaning inter-farms variability can be analysed to understand the interaction between individual and collective management. Using simulation, simple techniques to be implemented by individual farmers that are likely to improve the whole system performance were tested. This study involved the following four scenarios, the results of which will be discussed in section 3:

- $\mathrm{S}_{0}$ : reference scenario that considers slurry management based on current farm characteristics;

- $\mathrm{S}_{1}$ : increasing storage and spreading capacities of pig farms to better comply with slurry on farm;

- $\mathrm{S}_{2}$ : covering slurry tanks to decrease water evaporation, rain addition, and ammonia volatilization;

- $\mathrm{S}_{3}$ : saving water (e.g. washing the piggery, watering animals) to produce more concentrated slurry.

\section{SIMULATION RESULTS}

\subsection{Inter-farms variability for several environmental indicators}

The environmental indicators used to compare the pig farms committed to the collective spreading plan were:

- Ammonia emissions $\left(\mathrm{N}-\mathrm{NH}_{3}\right)$ at storage in pig farms and after spreading in both pig and land loaners' farms, which impact on the eutrophication and acidification criteria. $\mathrm{NH}_{3}$ emitted at storage is proportional to the area of the slurry tank, temperature and $\mathrm{N}$ $\mathrm{NH}_{4}{ }^{+}$concentration of slurry.

- Methane emissions $\left(\mathrm{C}-\mathrm{CH}_{4}\right)$ at storage in pig farms. They vary with slurry volume and temperature.

- Water pollution risk by nitrates $(\mathrm{N}$ $\mathrm{NO}_{3}$ ), which impacts eutrophication, is assessed by slurry stocks overflowing considered, implicitly, as spreading in excess or outside authorised periods.

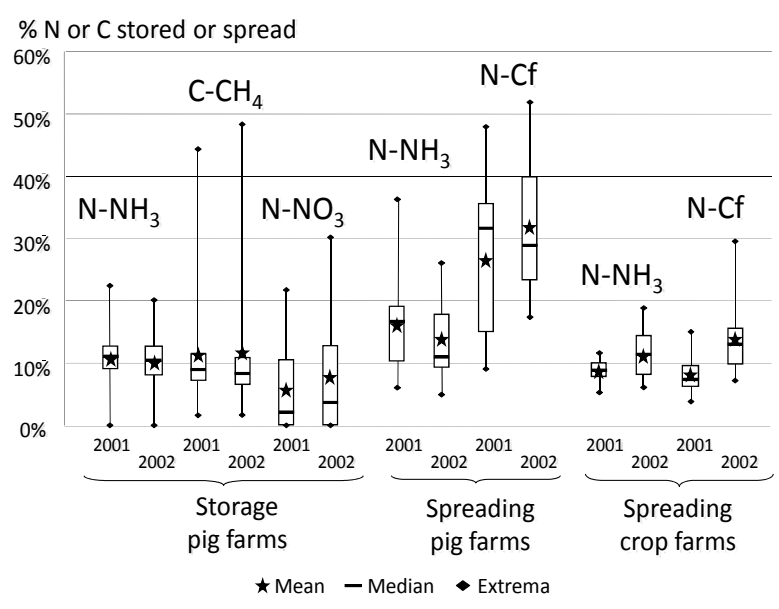

Figure 2. Inter-farm variability of environmental indicators for pig and crop farms based on their current characteristics $\left(\mathrm{S}_{0}\right)$

- Amount of nitrogen that should be added as chemical fertilizers (N-Cf) to compensate for the possible lack of slurry application and $\mathrm{N}$ losses by volatilization. Using synthetic fertilizers has impacts on both climate change and nonrenewable energy consumption.

- $\quad$ Spreading and transport times, as directly related to the consumption of non-renewable energy and greenhouse gases emissions by vehicles.

Simulation of the $\mathrm{S}_{0}$ reference scenario showed large inter-farm variability for most indicators when considering the extremes (Fig. 2). These values were linked to the slurry storage facilities, spreading equipment and cropping plans of individual farms. NH3 emissions at spreading varied according to the slurry quality and the amount applied, as well as the type of crop which determines the use of slurry injection (e.g. deep injection is never performed on wheat and grassland). The variability was lower in the case of spreading on land loaners' crops as the quality of slurry issued from fattening pigs was less variable than that of Mix slurry. The Terragator $^{\circledR}$, which allows deep soil injection, was always used for spreading at land loaners' whereas it was not 
used on pig farms. The quantity of added chemical fertilizers was lower for land loaners' crops than for pig farm crops, because of the priority given to the collective plan.

Considering two contrasting climatic years (wet late winter in 2001, dry late winter in 2002) inter-farm variability was not equivalent across years for all indicators. Added chemical fertilizer was on average higher in 2002 than in 2001 (Fig. 2), because of higher $\mathrm{NH}_{3}$ emissions at spreading, due to the slurry being more concentrated in nitrogen, and of higher temperature.

\subsection{Comparing the performance of two pig farms}

As an example, farms F8 and F11, which contain similar livestock (about 1000 sows each) and crops (wheat, rape, maize and grassland), exhibited very different environmental performances (Fig. 3). F8, with 69 ha, often had very low slurry stocks (Fig. 3a, lower curves) which resulted in little overspreading (lower curve in Fig. 3b) and few $\mathrm{NH}_{3}$ and $\mathrm{CH}_{4}$ releases at storage (Fig. $3 \mathrm{c}$ and $3 \mathrm{~d}$ lower curves). Whereas F11, with 100 ha, often had high slurry stocks (Fig. 3a upper curves), with a mean FP filling rate of 0.81 vs. 0.35 for $\mathrm{F} 8$, which resulted in large overspreading (upper curve in Fig. 3b) and higher gas emissions (Fig. $3 \mathrm{c}$ and $3 \mathrm{~d}$ upper curves). There are some large management differences between these farms. Firstly, they have different cropping plans: F8 has relatively few winter cereals (10 ha), a significant acreage of grassland (24 ha) and good soils,
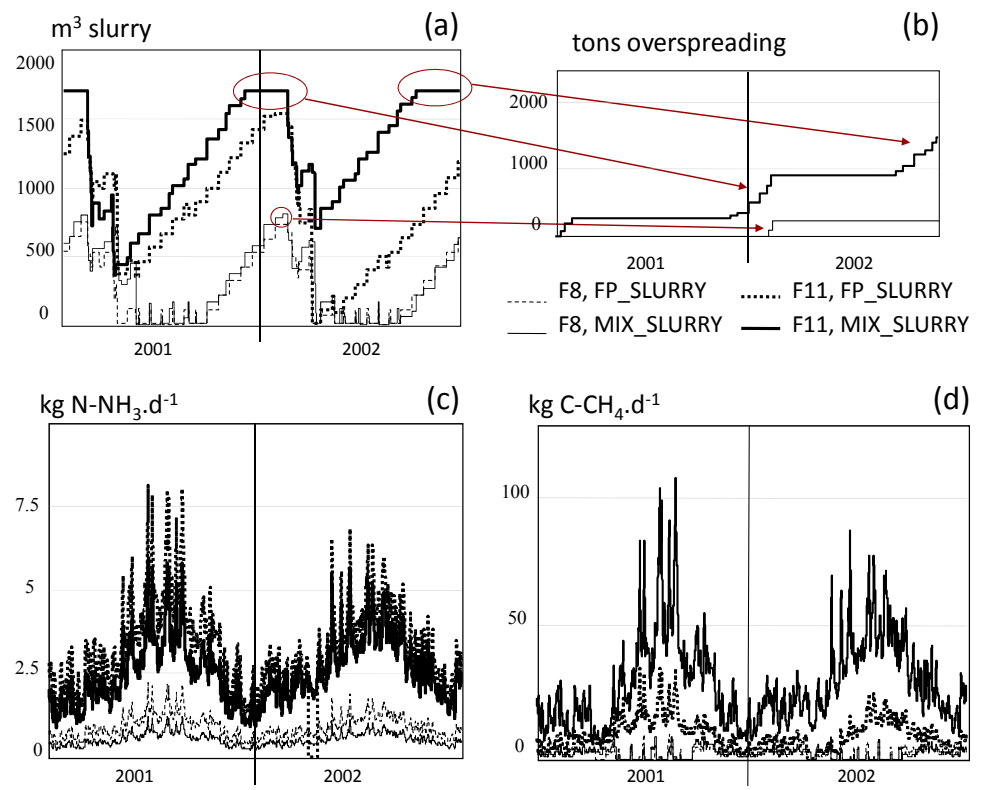

$\mathrm{kg} \mathrm{C}-\mathrm{CH}_{4} \cdot \mathrm{d}^{-1}$

(d)

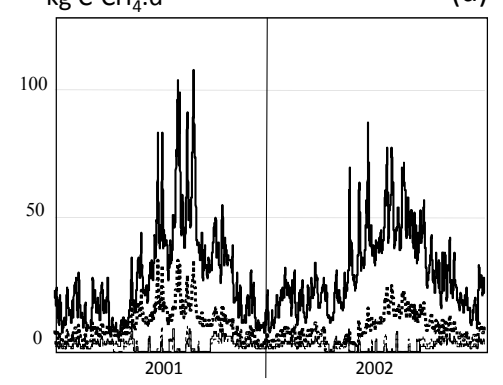

Figure 3. Two-year evolution of slurry stocks, accumulated overspreading and gaseous emissions at storage in pig farms F8 and F11.

while F11 has half its acreage planted to wheat (50 ha), most of which (44 ha) is grown on poorly drained soil, and very little grassland (4 ha). Therefore, F11 spread little slurry on its own crops (4 $600 \mathrm{~m}^{3}$ vs. 6500 $\mathrm{m}^{3}$ for F8) but this was compensated by more export to the collective plan $\left(1400 \mathrm{~m}^{3} \mathrm{vs} .875 \mathrm{~m}^{3}\right)$. Overall, F11 processed similar amounts of slurry to F8 (17\% less). Secondly, F11 has double the storage capacity with an open surface area of 4.5 (FP slurry) to 7 (Mix slurry) times the area of F8. Therefore, F11's mean slurry stock retention time was double F8's for Mix slurry (60 vs. 119 days) and quadruple for FP slurry (55 vs. 239 days). Combined these resulted in much higher emissions from F11 than F8 at storage: 3-6 times for $\mathrm{NH}_{3}$; 4-8 times for $\mathrm{CH}_{4}$ (FP and Mix slurry, respectively).

\subsection{Assessment of individual mitigation techniques}

Several alternatives were simulated for all farms and compared with the current situation $\left(\mathrm{S}_{0}\right)$. Increasing storage and spreading capacities of some deficient farms $\left(\mathrm{S}_{1}\right)$ mainly allowed one farm to reduce the $\mathrm{N}-\mathrm{NO}_{3}$ risk. The $\mathrm{N}$ lost: $\mathrm{N}$ produced ratio was reduced from $15 \%$ to $5 \%$ on average (Fig. 4 comparing $\mathrm{S}_{1}$ and $\mathrm{S}_{0}$ ). Storage and spreading emissions change very little and added chemical fertilizers decreased slightly. Covering slurry tanks $\left(\mathrm{S}_{2}\right)$ reduced ammonia emissions at storage, from $10 \%$ to $4 \%$ of $\mathrm{N}$ produced (comparing $\mathrm{S}_{2}$ and $\mathrm{S}_{0}$ in Fig. 4), and pig farm use of chemical fertilizers, because the $\mathrm{N}$ concentration of Mix slurry was higher. However, $\mathrm{CH}_{4}$ emissions were higher, increasing from 10 to $14 \%$ of $\mathrm{C}$ produced on average, because the mean slurry storage duration and stored volume were increased (Fig. 4). Ammonia emissions at spreading were relatively unmodified although the slurry was more concentrated. Because of this higher concentration, slurry deliveries and, consequently, total delivery times were decreased by as much as $30 \%$ (Fig. 5). This contributed to reduced non-renewable energy consumption and greenhouse gases emissions by trucks. Spreading time was only slightly reduced as more acreage was fertilised. Reducing slurry dilution $\left(\mathrm{S}_{3}\right)$ reduced the addition of chemical fertilizers, on both pig and crop farms' ( $\mathrm{S}_{3}$ vs. $\mathrm{S}_{0}$, Fig. 4), as well as reducing spreading and delivery times (Fig. 5). 


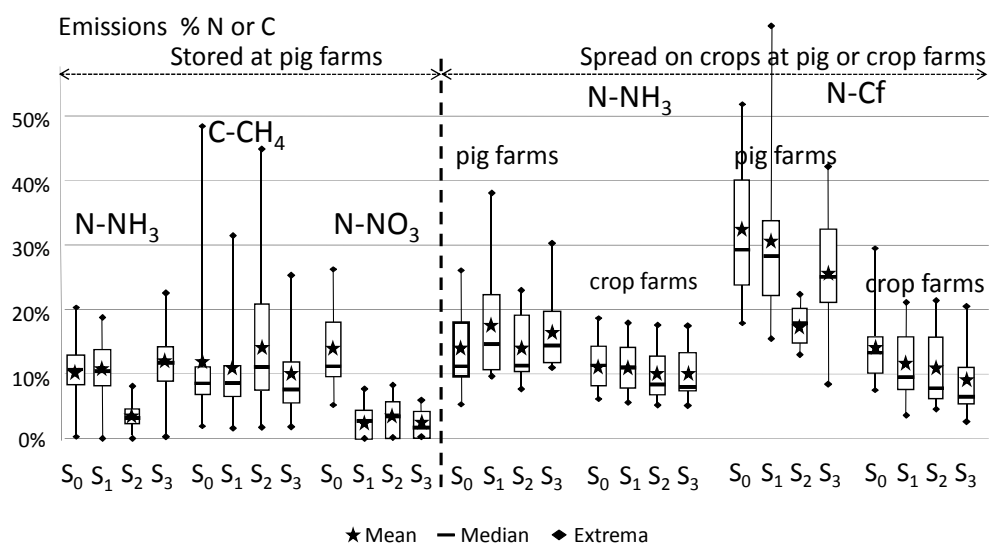

Figure 4. $\mathrm{NH}_{3}$ and $\mathrm{CH}_{4}$ emissions from slurry at storage, $\mathrm{NO}_{3}$ pollution risk, $\mathrm{NH}_{3}$ emission from slurry at spreading and added chemical fertilizers among pig or crop farm in scenarios $S_{0}-S_{3}$ in 2002 .

Other influential factors on farm emissions were also checked using COMET. For example, logistics of the collective management plan greatly influenced the capacity of spreading on pig farms. When the number of $25 \mathrm{~m}^{3}$-trucks used to collect slurry was reduced (e.g. from 6 to 4), the $\mathrm{NO}_{3}$ risk doubled and the alternative of chemical fertilizers was increased by $80 \%$ at land loaners', while being reduced by $15 \%$ on pig farms. Establishing flexible rules, like allowing pig farmers with too little storage capacity or constrained cropping plans to also use FP slurry instead of reserving it all to the collective plan, reduced the $\mathrm{NO}_{3}$ risk and decreased the use of additional chemical ferti-

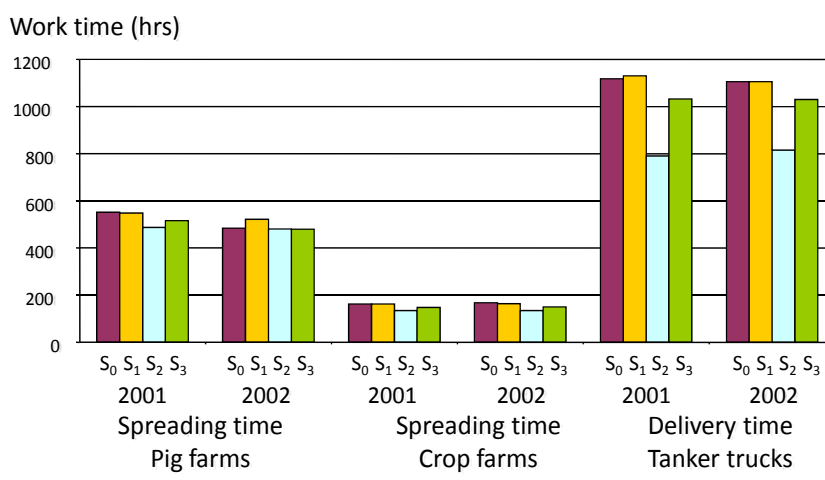

Figure 5. Annual slurry spreading or delivery times according to scenarios $\mathrm{S}_{0}-\mathrm{S}_{3}$ in 2001 and 2002. lizer. Adapting collective management as much as possible to individual characteristics and constraints proved to be crucial for improving the whole system's overall functioning and environmental performance.

\section{DISCUSSION AND CONCLUSIONS}

This simulation study conducted using COMET and another using MELODIE shared the same general conclusion even they had different aims: simulating collective slurry management on a territory scale (this paper) vs. all pollutant flows within a farm (Chardon et al., 2007). The variability linked to farming structures and practices is very important and greatly influences the agronomic and environmental performances of farming systems. Therefore, using LCA based on average standard data or one-year data surveys on small sets of farms (Kanyarushoki et al., 2008) may be tenuous for comparing farming systems while disregarding their diversity and variability across-time. Although encompassing very useful aspects (multi-criteria, cradle to grave, etc.), it seems that LCA should be limited to studying relative improvements according to some key criteria, not assessing absolute impacts. In effect, using 'average' coefficients may lead to erroneous conclusions. For example, although the preliminary LCA study concluded the superiority of the Transfer scenario compared with on-farm treatment (cf. § 2.1), using COMET simulation outputs in a new LCA (see $\S 2.3$ ) put this result into perspective. Actually, this demonstrated that local idiosyncrasies (geographic, climatic, edaphic, structural, organisational, etc.) can greatly influence farm emissions. Accounting for these contingencies, simulation modelling can explain the part of uncertainty, commonly seen in LCA, which is linked to the diversity of farming systems and the concrete realization of farming activities (Payraudeau et al., 2007). The remaining uncertainty is linked to emission factors, which depend upon the availability of knowledge of the processes concerned. The use of COMET has shown that, as soon as accurate, adapted, models of biophysical processes are available, they can be easily combined into this operations management simulation framework.

This research emphasized that LCA and SM can be fruitfully combined to evaluate environmental impacts of farming systems. It demonstrated the necessity to address the collective territory level along with the dynam- 
Paillat and Guerrin, Combining individual and collective management of animal manure on a territory scale

ic interactions occurring within production systems. It is intended to pursue this promising reflection in the future.

\section{ACKNOWLEDGMENT}

This study was conducted in the research project Systèmes de production animales et développement durable supported by the French “Agence Nationale de la Recherche” (projet ANR-06-PADD-017 SPA/DD).

\section{REFERENCES}

Aubin, J., and van der Werf, H.M.G. (2009). Pisciculture et environnement, apports de l'Analyse de Cycle de Vie. Cahiers d'Agriculture, 18 (2), 220-226.

Basset-Mens, C., and van der Werf, H.M.G. (2005). Scenario-based environmental assessment of farming systems: the case of pig production in France. Agriculture Ecosystems and Environment, 105, 127-144.

Chardon, X., Rigolot, C., Baratte, C., Le Gall, A., Espagnol, S., Martin-Clouaire, R., Rellier, J.-P., Raison, C., Poupa, J.-C., and Faverdin, P. (2007). MELODIE: A whole-farm model to study the dynamics of nutrients in integrated dairy and pig farms. Paper presented at International Congress on Modelling and Simulation (Modsim 2007), Christchurch, New Zealand, December 10-13.

Guerrin, F. (2001). Magma: A model to help manage animal wastes at the farm level. Computers and Electronics in Agriculture, 33 (1), 35-54.

Guerrin, F. (2004). Simulation of stock control policies in a two-stage production system. Application to pig slurry management involving multiple farms. Computers and Electronics in Agriculture, 45 (1-3), 27-50.

Guerrin, F. (2009). Dynamic simulation of action at operations level. Journal of Autonomous Agents and Multi-Agent Systems, 18 (1), 156-185.

Guerrin, F., and Paillat, J.-M. (2003). Modelling biomass fluxes and fertility transfers: animal wastes management in the Reunion Island. Paper presented at International Congress on Modelling and Simulation (Modsim 2003), Townsville, Australia, July 14-17.

Kanyarushoki, C., van der Werf, H.M.G., Roger, F., and Corson, M. (2008). EDEN : un outil opérationnel pour l'évaluation environnementale des systèmes de production laitiers. Paper presented at Symposium Ecotech'08, Montoldre, France, October 21-22.

Lopez-Ridaura, S., Guerrin, F., Paillat, J.-M., van der Werf, H.M.G., and Morvan, T. (2007). Agronomic and environmental evaluation of collective manure management for a group of farms. Paper presented at International Symposium on Methodologies for Integrated Analysis of Farm Production Systems (Farming Systems Design 2007), Catania, Italy, September 10-12.

Lopez-Ridaura, S., van der Werf, H.M.G., and Paillat, J.-M. (2008a). Environmental evaluation of transfer and treatment of excess pig slurry by life cycle assessment. Journal of Environmental Management, 90, 1296-1304.

Lopez-Ridaura, S., van der Werf, H.M.G., Paillat, J.-M., and Guerrin, F. (2008b). Environmental systems analysis of agricultural systems: Coupling dynamic simulation models with life-cycle assessment. Paper presented at 8th International Conference on Ecobalance, Tokyo, Japan, December 10-12.

Loyon, L., Guiziou, F., Beline, F., and Peu, P. (2007). Gaseous emissions $\left(\mathrm{NH}_{3}, \mathrm{~N}_{2} \mathrm{O}, \mathrm{CH}_{4}\right.$ and $\left.\mathrm{CO}_{2}\right)$ from the aerobic treatment of piggery slurry-Comparison with conventional storage systems. Biosystem Engineering, 97, 472-480.

Morvan, T., and Leterme, P. (2001). Vers une prévision opérationnelle des flux de N résultant de l'épandage de lisier : paramétrage d'un modèle dynamique de simulation des transformations de l'azote des lisiers (STAL). Ingénieries, 26, 17-26.

Paillat, J.-M., Lopez-Ridaura, S., Guerrin, F., van der Werf, H.M.G., Morvan, T., and Leterme, P. (2009). Simulation de la faisabilité d'un plan d'épandage de lisier de porc et conséquences sur les émissions gazeuses au stockage et à l'épandage. Journées Recherche Porcine, 41, 271-276.

Payraudeau, S., and van der Werf, H.M.G. (2005). Environmental impact assessment for a farming region: a review of methods. Agriculture, Ecosystems an Environment, 107 (1), 1-19.

Payraudeau, S., van der Werf, H.M.G., and Vertès, F. (2007). Analysis of the uncertainty associated with the estimation of nitrogen losses from farming systems. Agricultural Systems, 94, 416-430.

Pelletier, F., Godbout, S., Larouche, J.-P., Lemay, S., and Marquis, A. (2006). Ammonia emissions from swine manure storage tank. Paper presented at $12^{\text {th }}$ International Conference on Technology for Recycling of Manure and Organic Residues in a Whole-Farm Perspective (Ramiran), Aarhus, Denmark, September 11-13.

Rigolot, C., Espagnol, S., Robin, P., Hassouna, M., Béline, F., Paillat J.-M., and Dourmad, J.-Y., 2010. Mathematical modelling of manure production by pigs. Part II: $\mathrm{NH}_{3}, \mathrm{~N}_{2} \mathrm{O}$ and $\mathrm{CH}_{4}$ emissions and nutrient and matter flows in animal house and during manure storage and treatment. Animal, 4 (8), 1413-1424. 